\title{
Lumbalgia por síndrome de Bertolotti
}

\author{
Low back pain due to Bertolotti's syndrome \\ Luis Gerardo Domínguez Carrillo, * Luis Gerardo Domínguez Gasca ${ }^{\ddagger}$ \\ Citar como: Domínguez CLG, Domínguez GLG. Lumbalgia por síndrome de Bertolotti. \\ Acta Med. 2021; 19 (1): 126-127. https://dx.doi.org/10.35366/98582
}

Paciente masculino de 33 años de edad con antecedentes de cuadros de lumbalgia moderada desde los 18 años de edad (de uno a tres cuadros por año, con duración de síntomas de menos de una semana por episodio); relata haber subido 7 kilos de peso en el último año, por lo que decidió someterse a programa de ejercicio en los dos últimos meses (trote de 5 kilómetros alternando con ejercicios aeróbicos en gimnasio). A los 10 días del inicio de ejercicio presentó lumbalgia con intensidad de 6 a 8 en EVA, con irradiación a nalga derecha y cara anterolateral de muslo izquierdo por arriba de rodilla que no respondió a antiinflamatorios habituales utilizados por el paciente (naproxeno 500 mg BID), por lo que acude a rehabilitación. A la exploración: marcha de características normales; postura: elevación discreta de hombro derecho, desnivel pélvico por acortamiento de miembro pélvico derecho, abdomen globoso por panículo adiposo e hiperlordosis lumbar. Dolor a la presión de músculos paravertebrales lumbares bilateral que se incrementa con movimientos de rotación, dolor a la presión de articulación sacroiliaca derecha, siendo positivos los signos de Patrick, Gaenslen y de Yeoman para sacroiliaca derecha y negativos para la izquierda; signo de Lasègue negativo bilateral, arcos de movimiento de extremidades pélvicas completos, examen clínico muscular indicando: abdominales 3/5, resto $5 / 5$; sensibilidad, reflejos osteotendinosos, pulsos y llenado capilar normales. Con diagnóstico de síndrome facetario L4/L5 izquierdo y probable sacroileitis derecha. Se solicitaron radiografías simples anteroposterior y lateral de columna lumbosacra en bipedestación (Figura 1) encontrando: sacralización de la quinta vértebra lumbar con megaapófisis transversa derecha (flecha gris) al compararse con apófisis transversa izquierda de L5 (cabeza de flecha) formando pseudoarticulación con el ilion derecho (flecha negra) y artrosis facetaria L4/L5 izquierda (flecha blanca delgada), asociada con laterolistesis derecha del cuerpo

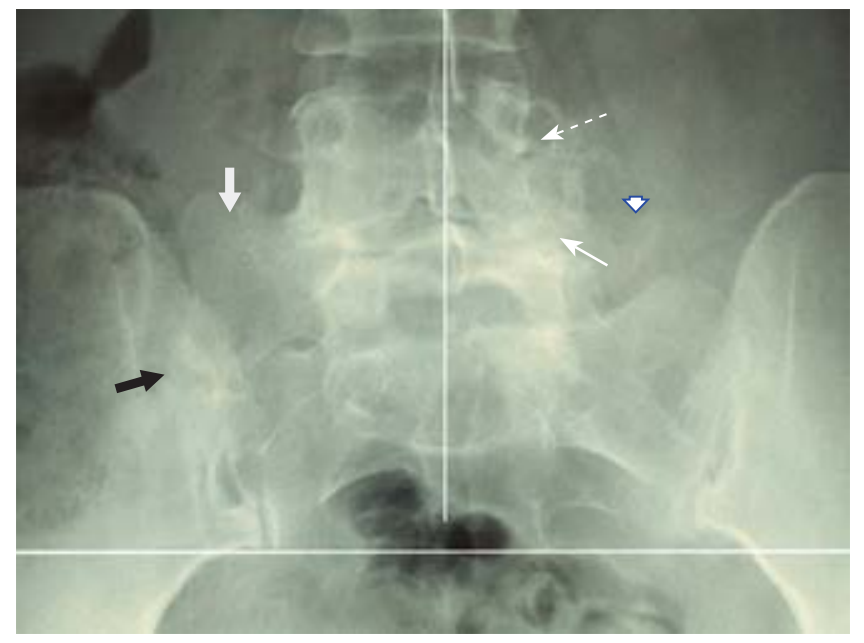

Figura 1: Radiografía anteroposterior de columna lumbosacra (acercamiento) que muestra: desnivel pélvico por acortamiento de miembro pélvico derecho, sacralización de la quinta vértebra lumbar con megaapófisis transversa derecha (flecha gris) al compararse con apófisis transversa izquierda de L5 (cabeza de flecha), formando pseudoarticulación con el ilion derecho (flecha negra) y artrosis facetaria L4/L5 izquierda (flecha blanca delgada), asociada a laterolistesis derecha del cuerpo de L4 (flecha punteada).

* Especialista en Medicina de Rehabilitación. Catedrático de la Facultad de Medicina de León, Universidad de Guanajuato. México.

₹ Ortopedista. División de Cirugía del Hospital Ángeles León. León, Guanajuato, México.

\section{Correspondencia:}

Dr. Luis Gerardo Domínguez Carrillo

Correo electrónico: Igdomínguez@hotmail.com

Aceptado: 21-11-2019.

www.medigraphic.com/actamedica 
de L4 (flecha punteada). Se estableció diagnóstico de síndrome de Bertolotti tipo IIA.

Se solicitó a anestesiología efectuar prueba terapéutica con infiltración (bajo fluoroscopia) con lidocaína al $2 \%$ sin epinefrina de pseudoarticulación transverso-ilion y de faceta articular L4/L5 izquierda, desapareciendo sintomatología, por lo que se decidió la infiltración con metilprednisolona $20 \mathrm{mg}$ a cada sitio antes mencionado, suspendiendo trote y gimnasio. Tres semanas después (con paciente asintomático) se inició programa de rehabilitación con ejercicios de higiene de columna y fortalecimiento de músculos abdominales, asociado con programa dietético por nutrióloga y rutina de cuatro días/semana a programa de natación. Con seguimiento a seis meses, el paciente permanece asintomático, ha bajado 10 kilos de peso y no ha requerido ninguna medicación.

El síndrome de Bertolotti ${ }^{1}$ (SB) se define por la presencia de lumbalgia y/o síntomas radiculares asociados con vértebra transicional lumbosacra congénita (VTLSC), en la cual existe fusión parcial o total o pseudoarticulación unilateral o bilateral de la apófisis transversa de L5 con el sacro o el ilion, lo cual implica alteración biomecánica que origina habitualmente artropatía de la articulación facetaria contralateral y suprayacente, tensión muscular del psoas iliaco y del cuadrado lumbar ipsilateral, llegando a producir además de síndrome facetario contralateral, compresión radicular por estrechamiento de los agujeros de conjunción y la presencia de discopatía de L4/L5. El SB es una causa importante de dolor lumbar en pacientes jóvenes; afecta de 4 a $8 \%$ de la población. ${ }^{2}$ La vértebra transicional lumbosacra congénita (VTLSC) es considerada la anomalía congénita más común de la columna lumbosacra con una incidencia general de 10 a 12, que puede variar con la fuente consultada entre 4 y $35 \%^{3}$; de acuerdo con la clasificación de Castellvi se divide en cuatro tipos, la VTLSC incluye la sacralización del cuerpo vertebral L5 y/o la lumbarización del segmento S1, que va desde procesos transversales agrandados hasta su fusión completa al sacro y/o ilion; los tipos más comunes de VTLSC que se asocian al síndrome de Bertolotti sintomático son los tipo I y tipo II; las variantes tipo III y tipo IV rara vez se presentan con síntomas referibles con pruebas confirmatorias y provocadoras de la vértebra transicional misma, existiendo experiencia limitada. ${ }^{4}$
La sintomatología típica del SB es: lumbalgia en la línea media o paramediana a la flexoextensión que se incrementa con la rotación lateral, la cual habitualmente se asocia con pruebas positivas de Patrick, de Gaenslen y de Yeoman indicando sacroileitis. El diagnóstico de SB se basa en hallazgos radiológicos y su correlación con la presentación clínica.

Las radiografías simples de la columna lumbosacra en vista anteroposterior suelen ser suficientes. La resonancia magnética debe utilizarse para la evaluación del disco intervertebral en caso de datos clínicos de compresión radicular. En cuanto a la presencia de vértebra transicional, el uso de la tangente de la cresta iliaca ${ }^{5}$ en las imágenes de resonancia magnética coronal tiene sensibilidad y especificidad relativamente confiables ( 81 y $64-88 \%$, respectivamente) para una numeración precisa de VTLSC, a diferencia de otros marcadores anatómicos paraespinales como la arteria renal derecha, la arteria mesentérica superior, la bifurcación aórtica y el cono medular, los cuales para la identificación de los niveles vertebrales no son confiables y no deben utilizarse. Cuando el tratamiento conservador del SB resulta insuficiente, existe la posibilidad de manejo quirúrgico con escisión de la megaapófisis transversa. ${ }^{1-6}$ Por último, dada la alta prevalencia de estas variantes anatómicas en la población general, el síndrome de Bertolotti debe considerarse en el diagnóstico diferencial de cualquier paciente con lumbalgia con o sin radiculopatía.

\section{REFERENCIAS}

1. Ju Cl, Kim SW, Kim JG, Lee SM, Shin H, Lee HY. Decompressive L5 transverse processectomy for Bertolotti's syndrome: a preliminary study. Pain Physician. 2017; 20 (6): E923-E932.

2. Jain A, Agarwal A, Jain S, Shamshery C. Bertolotti syndrome: a diagnostic and management dilemma for pain physicians. Korean J Pain. 2013; 26 (4): 368-373.

3. Adams R, Herrera-Nicol S, Jenkins AL 3rd. Surgical treatment of a rare presentation of Bertolotti's syndrome from Castellvi type IV lumbosacral transitional vertebra: case report and review of the literature. J Neurol Surg Rep. 2018; 79 (3): e70-e74.

4. Lian J, Levine N, Cho W. A review of lumbosacral transitional vertebrae and associated vertebral numeration. Eur Spine J. 2018; 27 (5): 9951004.

5. Gündüz N, Durukan G, Eser MB, Aslan A, Kabaalioğlu A. Role of iliac crest tangent in correct numbering of lumbosacral transitional vertebrae. Turk J Med Sci. 2019; 49 (1): 184-189.

6. Louie CE, Hong J, Bauer DF. Surgical management of Bertolotti's syndrome in two adolescents and literature review. Surg Neurol Int. 2019; 10: 135. 